\section{Obs Gyne Review - Journal of Obstetric and Gynecology}

2020 Volume 6 Number 2 March-April

\title{
Factors affecting the success rate of vaginal birth after cesarean section
}

\author{
Prabha J. S. ${ }^{1}$, N. Prema ${ }^{2 *}$ \\ DOI: https://doi.org/10.17511/joog.2020.i02.03 \\ 1 Sathya Prabha J., Assistant Professor, Department of Obstetrics and Gynaecology, Karpagam Faculty of Medical Sciences and Research, \\ Coimbatore, Tamil Nadu, India. \\ 2* Prema N., Associate Professor, Department of Obstetrics and Gynaecology, Karpagam Faculty of Medical Sciences and Research, \\ Coimbatore, Tamil Nadu, India.
}

Introduction: The success rate of vaginal birth after cesarean section (VBAC) varies among institutions and health care providers. It is also affected by various antepartum, intrapartum factors as well as the difference in the obstetric population. Objectives: The main aim of the study is to determine the factors that affect the success rate of vaginal birth after cesarean section. This will help us to choose the right patients for VBAC thereby decreasing the complications of an emergency cesarean section. Methods: This is a prospective, cohort study done over a period of twelve months. Based on the patient's preference a total of 211 women were divided into two groups either a trial of labor after cesarean section (TOLAC) or elective repeat cesarean section (ERCS) group. VBAC group was compared with the failed trial of labor group to determine the factors affecting the success rate. Result: The success rate of VBAC was found to be $47.9 \%$. About $15 \%$ of failed VBAC was due to the tendency to abandon a TOLAC midway. The success rate of VBAC increased in women with previous vaginal delivery and in those who went into spontaneous labor. Epidural was found to be safe to use in the trial of the labor group. Conclusion: Women with factors that increase the likelihood for vaginal delivery following cesarean section should be motivated well and referred to a tertiary center to improve the success rate as well as to reduce the maternal and fetal morbidity.

Keywords: Elective repeat cesarean section, Trial of labor after cesarean section, Vaginal birth after cesarean section

\section{Corresponding Author}

Prema N., Associate Professor, Department of Obstetrics and Gynaecology, Karpagam Faculty of Medical Sciences and Research, Coimbatore, Tamil Nadu, India.

Email: drnprema@gmail.com
How to Cite this Article

To Browse

Prabha JS, Prema N. Factors affecting the success rate of vaginal birth after cesarean section. Obs Gyne Review J Obstet Gynecol. 2020;6(2):46-52. Available From https://obstetrics.medresearch.in/index.php/joog/art icle/view/92

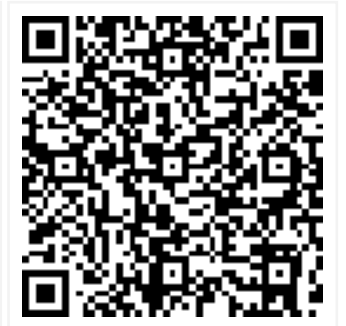

\begin{tabular}{|c|c|c|c|c|c|}
\hline & $\begin{array}{c}\text { Manuscript Received } \\
28-02-2020\end{array}$ & $\begin{array}{c}\text { Review Round } 1 \\
07-03-2020\end{array}$ & $\begin{array}{c}\text { Review Round } 2 \\
12-03-2020\end{array}$ & Review Round 3 & $\begin{array}{c}\text { Accepted } \\
16-03-2020\end{array}$ \\
\hline & $\begin{array}{c}\text { Conflict of Interest } \\
\text { No }\end{array}$ & $\begin{array}{c}\text { Funding } \\
\mathrm{Nil}\end{array}$ & $\begin{array}{c}\text { Ethical Approval } \\
\text { Yes }\end{array}$ & $\begin{array}{c}\text { Plagiarism X-checker } \\
15 \%\end{array}$ & Note \\
\hline OPEN & $\begin{array}{l}\text { (c) } 2020 \text { by } \subseteq \\
\text { ACCESS }\end{array}$ & $\begin{array}{l}\text { Prema N. and Pub } \\
\text { article licensed und } \\
\text { https://creativeco }\end{array}$ & $\begin{array}{l}\text { dharth Health Rese } \\
\text { Commons Attributic } \\
\text { censes/by/4.0/ unp }\end{array}$ & $\begin{array}{l}\text { I Welfare Society. This is } \\
\text { ional License } \\
\text { t.0]. }\end{array}$ & \\
\hline
\end{tabular}




\section{Introduction}

The optimum management of the woman with a history of previous cesarean section has been debated for many years. Both ERCS and TOLAC carry a high risk of adverse outcomes. A failed trial of labor leading to an emergency cesarean section carries the highest risk and vaginal delivery the lowest. So the decision regarding delivery is like handling a double-edged sword analyzing the benefits versus the risk.

The cesarean delivery rate has plateaued at $32 \%$; concurrently, after peaking in the mid-1990s, trial of labor after cesarean (TOLAC) rates have declined to $25 \%$ [1]. The success rate of VBAC is around 56 and $80 \%[2,3,4]$. Although TOLAC is appropriate for many women, several factors increase the likelihood of a failed trial of labor, which in turn is associated with increased maternal and perinatal morbidity when compared with a successful trial of labor (VBAC) and elective repeat cesarean delivery. Therefore, assessing the likelihood of VBAC as well as the individual risks is important when determining who is an appropriate candidate for TOLAC [5].

The success rate of VBAC might be influenced by the availability and expertise of the health care workers. It also depends on the institutional resources, proper VBAC counseling, and the women's decision making is undergoing a trial of labor. Although VBAC was proven to be successful in developed countries there is a need more of studies in the Indian set up with the local population to improve the quality of health care and create awareness among patients. The main purpose of the present study is to analyze the factors determining the success rate of VBAC that will help us in the selection of candidates, better VBAC counseling, and set inclusion criteria thereby avoiding the morbidities associated with emergency cesarean section.

The highest success rates of VBAC are found among [4] women who have had a previous vaginal delivery, presenting in active labor and indication for the prior cesarean delivery being fetal malpresentation. Conversely, a reduced likelihood of a successful VBAC was seen following induction of labor especially with an unfavorable cervix and indication for previous cesarean being cervical dystocia. Low maternal age, high education, and western country of origin were associated with high TOLAC rates, and Iow TOLAC failure rates.
Maternity unit characteristics (size and region) contributed with effects on the same level as individual determinants studied [6]. The NICHD study showed unsuccessful compared with successful VBAC increased the risk of uterine rupture $(2.3 \%$ versus $0.1 \%)$, hysterectomy $(0.5 \%$ versus $0.1 \%$ ), transfusion (3.2\% versus $1.2 \%$ ) and endometritis ( $7.7 \%$ versus $1.2 \%$ ) [2]. VBAC offers distinct advantages over repeat cesarean since the operative morbidity and mortality are completely eliminated, the hospital stay is much reduced and the expenses involved are much less [7].

\section{Materials and Methods}

\section{Type of study: Prospective cohort study}

Setting: The study was carried out in the labor theatre, of G. Kuppuswamy Naidu Memorial Hospital. All the patients with previous cesarean section admitted in our hospital for safe confinement was chosen. Among this group, patients who gave consent for the study and satisfied the inclusion criteria were selected as the study sample.

Duration: 12 months

\section{Inclusion criteria}

- Women with previous one lower transverse cesarean section

- Single live fetus in cephalic presentation,

- Clinically adequate pelvis

- No contraindication for a vaginal birth.

\section{Exclusion criteria}

- Women with more than one cesarean Section

- Women with previous classical cesarean section, $\mathrm{T}$ or $\mathrm{J}$ shaped incision, previous low vertical incision

- Previous myomectomy/hysterotomy scar

- Previous uterine rupture/ history of postoperative wound infection

- Malpresentaton

- Previous lower transverse cesarean section less than 2 years

- Any contraindication to vaginal delivery.

Data collection: VBAC counseling was given after confirming the patient's eligibility for TOLAC. Eligible women were given an information sheet during pregnancy and written and informed consent was obtained. This study was a patient preference study. 
Women were allocated their preference for either a TOLAC or ERCS. The current study included a total of 211 women in the present study. A detailed history was taken and patients who preferred ERCS were taken up for elective section after completion of 38 weeks. In patients who preferred TOLAC, waited for spontaneous onset of labor. Induction after 39 completed weeks was done as per our hospital protocol in women who did not go into spontaneous labor. In some patients induction of labor was considered prior to 37 weeks in the presence of other risk factors. The method of induction was chosen according to Bishop's score. All women were closely monitored in labor with one to one nursing care. Women who abandon the trial of labor halfway were taken up for emergency cesarean section in view of maternal request. The percentage of this group of patients who contribute to the failed TOLAC was also studied. Electronic fetal monitoring was done in active labor. Any material or fetal abnormalities were identified and promptly acted on. An emergency cesarean section was done when necessary. Records were kept about maternal and perinatal complications in labor and after delivery during the period of hospital stay.

Data analysis: The SPSS 18.0 software package was utilized to analyze the data. All values were expressed as mean and standard deviation. The current study used the Chi-square test to calculate the significance of the association between groups. Software (SPSS) for windows version 16.00 (SPSS, 1999, SPSS Inc, New York). Microsoft word and excel have been used to generate graphs and tables.

Ethical approval: The study was approved by the Institutional Ethics Committee.

\section{Results}

Age distribution- Most of the patients of the study group were below 35 years that included 201 patients $(95.3 \%)$ and the rest $10(4.7 \%)$ were above the age of 35 years.

Table-1: Age distribution.

\begin{tabular}{|c|l|l|}
\hline Age & \multicolumn{1}{|c|}{ Number of cases } & \multicolumn{1}{c|}{ Percentage $(\%)$} \\
\hline$<35$ years & 201 & 95.3 \\
\hline$>35$ years & 10 & 4.7 \\
\hline
\end{tabular}

Gestational age- Out of 211 patients 168 (79.6\%) were above 37 weeks gestational age and 43 (20.4\%) were below 37 weeks gestational age.

\begin{tabular}{|l|l|l|}
\hline & \multicolumn{1}{|c|}{ Number of cases } & \multicolumn{1}{c|}{ Percentage } \\
\hline$<37$ weeks & 43 & 20.4 \\
\hline$>37$ weeks & 168 & 79.6 \\
\hline
\end{tabular}

Mode of delivery- Out of 211 patients, 119 (56.4\%) were willing for VBAC and had undergone a trial of labor, and $92(43.6 \%)$ were taken up for elective cesarean section in view of maternal request. Out of 119 patients in the TOLAC group, 57 had a successful VBAC and 62 had an emergency cesarean section. The success rate of VBAC was $47.9 \%$ in the study group.

Table-3: Mode of delivery.

\begin{tabular}{|l|l|l|}
\hline & \multicolumn{1}{|c|}{$\begin{array}{c}\text { Number of } \\
\text { cases }\end{array}$} & $\begin{array}{l}\text { Percentag } \\
\text { e }\end{array}$ \\
\hline Elective cesarean & 92 & 43.6 \\
\hline Trial of the labor group & 119 & 56.4 \\
\hline Vaginal birth after a cesarean section & 57 & 47.9 \\
\hline $\begin{array}{l}\text { Emergency cesarean section (failed trial of } \\
\text { labor) }\end{array}$ & 62 & 52.1 \\
\hline
\end{tabular}

Comparison between maternal age and mode of delivery

Out of 113 patients with age $<35$ years in the trial of labor group, 53 patients $(46.9 \%)$ had a successful VBAC. Out of 4 patients aged $>35$ years, $66.7 \%$ had a successful VBAC. Chisquare value 0.892 for the association between maternal age and mode of delivery is not significant $(\mathbf{p = 0 . 3 4 5 )}$. Hence there is no association found between maternal age and mode of delivery in the study group.

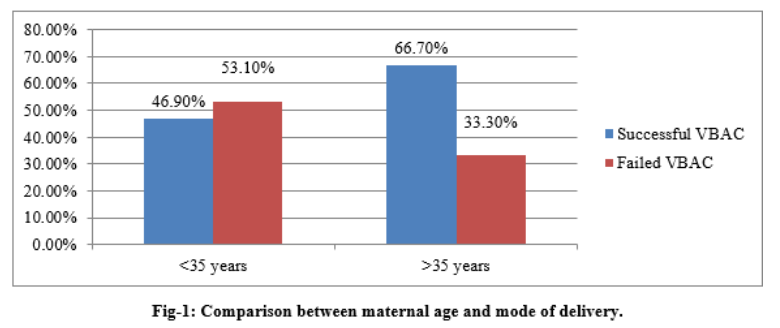

\section{Comparison between gestational age and mode of delivery}

In the TOLAC group, out of 29 patients with less than 37weeks gestational age, 15(51.7\%) had a successful VBAC. Among 90 patients with a gestational age below 37weeks $42(46.7 \%)$ patients had a successful VBAC. Chi-square value 0.225 for the association between gestational age and mode of delivery is not significant $(p=0.635)$. Hence there is no association found between gestational age and mode of delivery in the study group.

Table-2: Gestational age. 


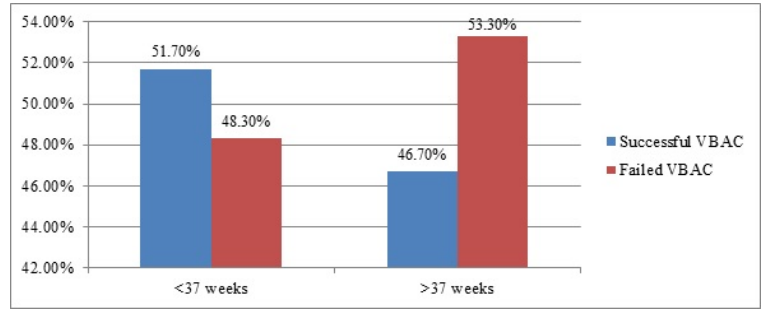

\section{Percentage of successful VBAC with previous vaginal delivery}

There were 13 cases of previous vaginal delivery of which 3 patients preferred elective cesarean section and of the remaining 10 patients who underwent a trial of labor had a $100 \%$ successful vaginal birth.

Chi-square value for the association between previous vaginal delivery and the success rate of VBAC is significant $(p=0.001)$.

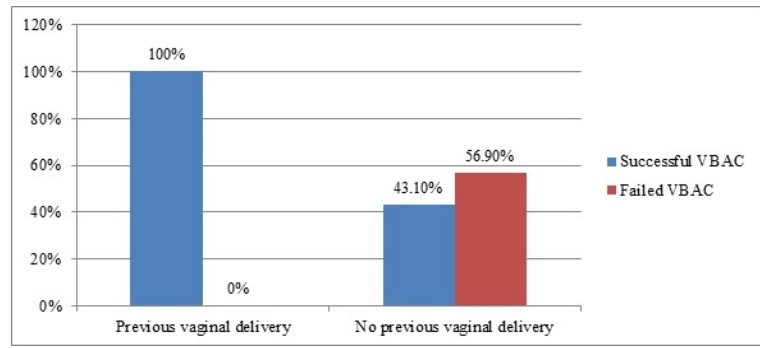

\section{Percentage of successful VBAC based on the} indications for previous cesarean deliveries

Patients with previous indications of malpresentation, fetal distress were found to have a VBAC success rate of $72.7 \%$ and $54 \%$ respectively. Patients with previous indications of failure to progress, the success rate of VBAC was $27.3 \%$. Although patients with previous indications of fetal distress \& malpresentation were found to have a high success rate of VBAC than failure to progress the chi-square value was not significant. Hence indications for previous cesarean deliveries in the study group are not found to affect the success rate of VBAC.

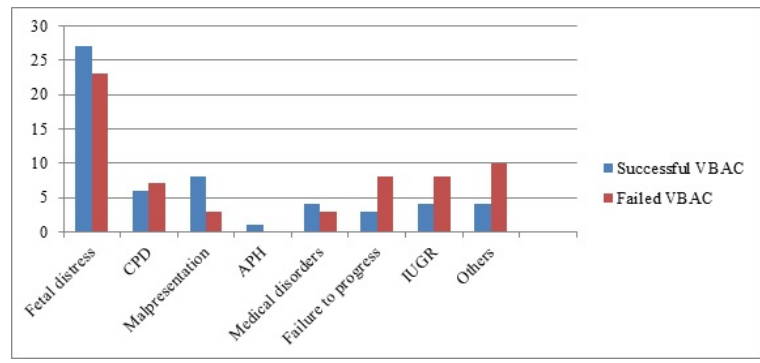

The success rate of VBAC in relation to onset of labor
In the present study group out of 119 women, $34(16.1 \%)$ went into spontaneous labor and in $85(40.3 \%)$ women labor was induced. The success rate of VBAC following spontaneous onset of labor was $70.6 \%$ and that following induction is $38.8 \%$. Chi square value for the association between spontaneous labor to the success rate of VBAC in the study group is significant $(p=0.002)$.

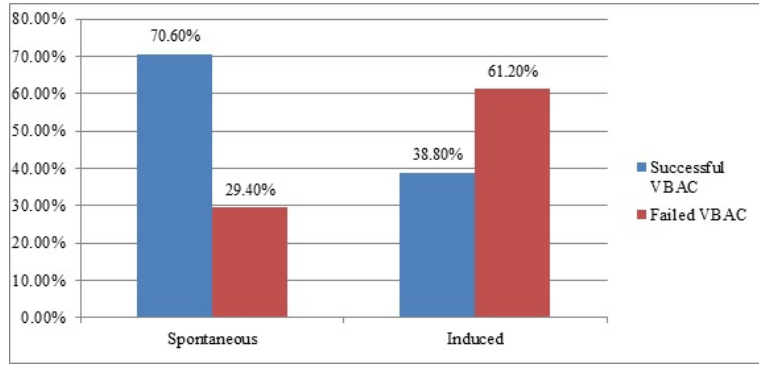

The success rate of VBAC in relation to epidural analgesia

Out of 119 patients, $33(15.6 \%)$ patients had epidural analgesia and $86(40.8 \%$ ) patients did not have epidural. Chi-square value for the association between epidural analgesia to the success rate of VBAC in the study group is significant $(p=0.000)$. Hence epidural is found to be safe in the trial of the labor group.

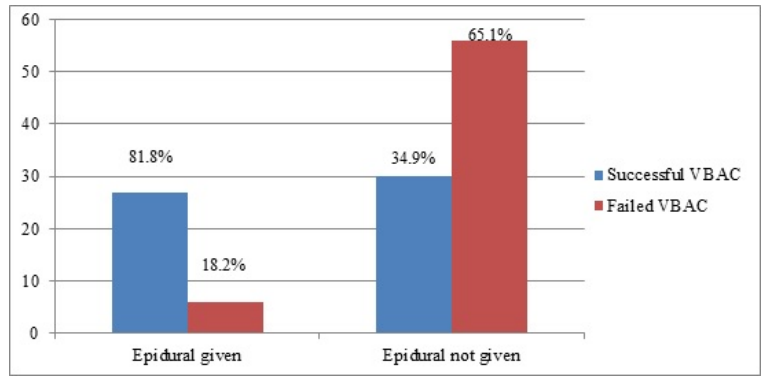

Fig-6: The success rate of VBAC in relation to epidural analgesia.

\section{Discussion}

211 women with previous cesarean sections were included in the study group. Most of the women of the study group were below 35 years that included 201 patients (95.3\%) and the rest $10(4.7 \%)$ were above the age of 35 years. 168 (79.6\%) women were above 37 weeks gestational age and 43 (20.4\%) were below 37 weeks gestational age. Out of 211 women, 119 (56.4\%) were willing for VBAC and had undergone a trial of labor and 92 (43.6\%) were taken up for elective cesarean section in view of maternal request. 
In a study by Landon et al [2], Stone and associates [3], Mc Mohan, and associates [4] successful rates of between $56 \%$ and $80 \%$ are reported. ACOG 2019 reported that generally, 60 to 80 percent of TOLAC result in vaginal delivery. In a meta-analysis done in sub-Saharan Africa involving 14 studies [8], the success of vaginal birth after the cesarean section was $69 \%$. The success rate of VBAC was $47.9 \%$ in the study group.

The study done by Grobman et al [9], was to determine whether and to what degree, the change in VBAC rate was due to a change in the characteristics of the obstetric population and the tendency to abandon a TOLAC once it has been initiated. The study was done at eight academic centers during a 4-year period (1999-2002). Of the $5334(55.3 \%)$ who underwent a TOLAC, VBAC rate underwent a steady decline: $51.8 \%$ to $45.1 \%$ to $37.4 \%$ to $29.8 \%(P<0.001)$. Although there were some changes noted in the characteristics of the population, the most pervasive reason for this decline was that women became increasingly likely to forego a TOLAC, regardless of their likelihood of vaginal delivery. In the present study out of 62 women $(52.1 \%)$ who had an emergency LSCS in the trial of labor group, 33(15.6\%) deferred the trial of labor halfway and wanted an emergency LSCS. About $15 \%$ of failed VBAC was due to the tendency to abandon a TOLAC once it has been initiated. Based on these results, it appears that the cause for change in the VBAC rate is multifactorial and it varies with the obstetric population.

Lehmann and colleagues, 2020 [6] reported that women over age 39 were less likely to have a successful VBAC and more likely to experience TOLAC associated complications. In the present study, there was no association found between maternal age and mode of delivery $(p=0.345)$.

Durnwald and associates 2006 [10], Quinones, and colleagues, 2005 [11] reported that women who attempt a trial of labor with a preterm fetus have a successful vaginal delivery rate. Sentilhils and coworkers 2013 [12] reported that women with preterm fetuses have an increased likelihood of VBAC. In the present study group, there was no significant association found between gestational age and mode of delivery $(p=0.635)$.

Landon MB and his coworkers [13] found that women who have had a vaginal delivery before or after their previous cesarean delivery are significantly more likely to have a successful TOLAC
Than those who have never delivered vaginally (odds ratio for successful TOLAC with prior vaginal delivery 3.90, 95\% CI 3.60-4.30; with prior VBAC $4.76,95 \%$ CI 4.35-5.26)(14,15). The present study results were similar thereby concluding that women with previous vaginal delivery have a higher success rate of VBAC $(p=0.001)$.

Guise et al [16] concluded that the rate of successful TOLAC based on indication for prior cesarean delivery was 75 percent for fetal malpresentation, 60 percent for nonreassuring fetal heart rate pattern, and 54 percent for failure to progress or cephalopelvic disproportion. Peaceman and associates 2006 [17], found that those with dystocia as the original indication had a significantly lower success rate compared with those with other indications- 54 versus 67 percent, respectively. Place et al 2019 [18] reported TOLAC as a feasible option to scheduled repeat $\mathrm{CS}$ in women with a history of failed induction of labor dystocia. However, women with no previous vaginal delivery, diabetes, or suspected neonatal macrosomia $(\geq 4500 \mathrm{~g})$ may be at increased risk for failed TOLAC. In the present study group, indications for previous cesarean deliveries are not found to affect the success rate of VBAC $(p=0.200)$.

Guise et al [16] concluded that women in spontaneous labor or with a high Bishop score are more likely to have successful TOLAC than women who are being induced or who have low Bishop scores. (Odds ratio for successful TOLAC with spontaneous labor, induction, augmentation 1.0, $0.50,0.68$, respectively). In the present study, the success rate of VBAC is found to be increased in the spontaneous labor group. TOLAC should be encouraged for women with a previous vaginal delivery either before or after the cesarean, a favorable Bishop score or spontaneous labor, and for preterm births [12]. Landon and co-workers, 2005 [13] have concluded that epidural analgesia may safely be used during a trial of labor. Out of 119 women $33(15.6 \%)$ had epidural analgesia and $86(40.8 \%)$ did not have epidural. Chi-square value for the association between epidural analgesia to the success rate of VBAC in the study group is significant $(p=0.000)$. So epidural is found to be safe in the trial of the labor group.

Limitations: It is a short term study, therefore long term complications of ERCS such as bowel and bladder adhesions, future pregnancy complications could not be studied. 


\section{Conclusions}

The success rate of VBAC was found to be $47.9 \%$ in the study sample. This might be due to the fact that the study was done in an Indian population, the characteristics might be different from that of the other race. It also depends on the acceptance and perseverance of the women to undergo TOLAC and their mental strength to withstand labor. It also depends upon the hospital resources, expertise, and availability of the physician. In a low resource setting in India, TOLAC is a nightmare.

\section{What does the study add to the existing knowledge?}

This present study might boost the obstetricians in an Indian tertiary care setup to counsel more for TOLAC. During counseling, the decision about the mode of delivery should be discussed with the patient. The individual risk factors for TOLAC, risk of uterine rupture, and the possibility of future pregnancy should be discussed during counseling. Increased success rate with previous vaginal deliveries and with spontaneous labor shall be informed during the counseling. Instead of opting for ERCS at all levels of health care providers, women willing for VBAC should be counseled and referred for institutional deliveries to improve the success rate of VBAC.

\section{Author's contribution}

Dr. Sathya Prabha J.: Sample collection and manuscript preparation. Dr. Prema N.: Statistical analysis and manuscript preparation.

\section{Reference}

01. James S, Caughey AB. Vaginal Birth After Cesarean Trends- Which Way Is the Pendulum Swinging?. Obstet Gynecol Clin North Am. 2017;44(4)655-666. doi: [10.1016/j.ogc. 2017. 08.006] [Crossref]

02. Landon MB, Hauth JC, Leveno KJ, Spong $\mathrm{CY}$, Leindecker S, Varner MW, Moawad $\mathrm{AH}$, et al. for the National Institute of Child Health and Human Development Maternal-Fetal Medicine Units Network- Maternal and perinatal outcomes associated with trial of labour after prior caesarean delivery. N Engl J Med. 2004;351(25) 2581-9. doi: [10.1056/nejmoa040405] [Crossref]
03. Stone C, Halliday J, Lumley J, Brennecke S. Vaginal birth after caesarean (VBAC)- a popul ation study. Paediatr Perinat Epidemiol. 2000; 14(4)340-8. doi: [10.1046/j.1365-3016.2000. 00299.x] [Crossref]

04. McMahon MJ. Vaginal birth after caesarean. Clin Obstet Gynecol. 1998;41(2)369-381. doi: [10.1097/00003081-199806000-00018] [Crossref]

05. ACOG Resource Center. ACOG Practice Bulletin No 205- Vaginal Birth After Cesarean Delivery. Obstet Gynecol. 2019;133(2)e110-e127. doi: [10.1097/AOG.0000000000003078] [Crossref]

06. Lehmann S, Baghestan E, Børdahl PE, Irgens LM, Rasmussen S. Low risk pregnancies after a cesarean section- Determinants of trial of labor and its failure. PLoS ONE. 2020;15(1)e0226894. doi: [10.1371/journal.pone.0226894] [Crossref:Crossref]

07. American Academy of paediatrics. American Academy of paediatrics and the American College of Obstetricians and Gynecologistsguidelines for perinatal care. 6th edition. 2007. [Crossref]

08. Boulvain M, Fraser WD, Brisson-Carroll G, Faron G, Wollast E. Trial of labour after caesarean section in sub-Saharan Africa- a meta-analysis. $\mathrm{Br}$ J Obstet Gynaecol. 1997;104(12)1385-1390. doi: [10.1111/j.1471-0528.1997.tb11008.x] [Crossref]

09. Landon Grobman WA, Lai Y, Landon MB, Spong $C Y$, Rouse DJ, Varner MW, et al. The change in the rate of vaginal birth after caesarean section. Paediatr Perinat Epidemiol. 2011;25(1)37-43. doi: [10.1111/j.1365-3016.2010.01169.x] [Crossref]

10. Durnwald CP, Rouse DJ, Leveno KJ, Sponge CY, Macpherson C, Varner MW, et al. The MaternalFetal Medicine Units Caesarean Registry- Safety and efficacy of a trial of labour in preterm pregnancy after a prior caesarean delivery. Am J Obstet Gynecol. 2006;195(4)1119-26. doi: [10. 1016/j.ajog.2006.06.047] [Crossref]

11. Place, K. , Kruit, H. , Tekay, A, Heinonen S, Rahkonen L. Success of trial of labor in women with a history of previous cesarean section for failed labor induction or labor dystocia- a retrospective cohort study. BMC Pregn Childbirth. 2019;19-176. doi: [10.1186/s12884019-2334-31 [Crossref] 
12. Sentilhes L, Vayssière C, Beucher G, Tharaux CD, Deruelle $P$, Diemunsch $P$, et al. Delivery for women with a previous cesarean- guidelines for clinical practice fromthe French College of Gynecologists and Obstetricians (CNGOF). Europe J Obstet Gynecol Reproduct Biol. Elsevier, 2013;170(1)25-32.

doi: [10.1016/j.ejogrb.2013.05.015]

[Crossref:Crossref]

13. Landon MB, Leindecker S, Spong CY, Mercer BM, Gabbe SG. National Institute of Child Health and Human Development Maternal-Fetal Medicine Units Network. The MFMU Caesarean Registryfactors affecting the success of trial of labour after previous caesarean delivery. Am J Obstet Gynecol.

2005;193(3):1016-1023.

doi:

[10.1016/j.ajog.2005.05.066] [Crossref]

14. Silver RM, Landon MB, Rouse DJ, Leveno KJ, Sponge CY, Thom EA et al. National Institute of Child Health and Human Development MaternalFetal Medicine Units Network- Maternal morbidity associated with multiple repeat caesarean deliveries. Obstet Gynecol. 2006;107(6)1226-1232.

[Crossref]

15. Chauhan SP, Martin JN Jr, Henrichs CE, Morrison JC, Magann EF. Maternal and perinatal complications with uterine rupture in 142,075 patients who attempted vaginal birth after caesarean delivery- A review of the literature. Am J Obstet Gynecol. 2003;189(2)408-417. doi: [10.1067/s0002-9378(03)00675-6] [Crossref]
16. Guise J-M, Eden $K$, Emeis C, Denman MA, Marshall N, Fu R, Janik R, Nygren P, Walker M, cDonagh M. Vaginal Birth After Caesarean- New Insights. Evidence Report/Technology Assessment No191. (Prepared by the Oregon Health \& Science University Evidence-based Practice Center under Contract No 290-200710057-I).

AHRQ Publication No 10-E003. Agency for Healthcare Research and Quality, Rockville, MD2010. [Article] [Crossref]

17. Peaceman AM, Gersnoviez $R$, Landon $M B$, Sponge $\mathrm{CY}$, Leveno $\mathrm{KJ}$, Varner $\mathrm{MW}$ et al. National Institute of Child Health and Human Development Maternal-Fetal Medicine Units Network- The MFMU caesarean registry- Impact of fetal size on trial of labour success for patients with previous caesarean for dystocia. Am J Obstet Gynecol. 195-1127, 2006;195(4)1127-1131.

doi: [10.1016/j.ajog.2006.06.003] [Crossref]

18. Quinones JN, Stamilio DM, Paré E, Peipert JF, Stevens $E$, Macones JA. The effect of prematurity on vaginalbirth after caesarean delivery- Success and maternal morbidity. Obstet Gynecol. 2005;105(3)519-524. doi: [Article:10.1097/01.aog.0000153493.15922.85] [Crossref] 